\title{
Regadenoson use in patients with chronic obstructive pulmonary disease: the state of current knowledge
}

This article was published in the following Dove Press journal:

International Journal of COPD

22 January 2014

Number of times this article has been viewed

\author{
Yasmeen Golzar ${ }^{1,2}$ \\ Rami Doukky ${ }^{1,2}$ \\ 'Division of Adult Cardiology, \\ John H Stroger Jr, Hospital of \\ Cook County, ${ }^{2}$ Division of \\ Cardiology, Rush University \\ Medical Center, Chicago, IL, USA
}

Correspondence: Rami Doukky Rush University Medical Center, Section of Cardiology, 1653 W Congress Parkway, Chicago, IL 606I2, USA $\mathrm{Tel}+\mathrm{I} 3 \mid 29424655$

$\mathrm{Fax}+\mathrm{I} 3125633213$

Email rami_doukky@rush.edu

\begin{abstract}
Stress testing is challenging in patients with chronic obstructive pulmonary disease (COPD). Functional capacity is generally decreased in this patient population, limiting patients' ability to achieve physiologic stress through exercise. Additionally, due to emphysematous changes, COPD patients tend to have poor acoustic windows that impair the quality and therefore diagnostic accuracy of stress echocardiography techniques. Pharmacologic stress myocardial perfusion imaging (MPI) testing is also problematic, particularly due to the concern for adenosine-induced bronchoconstriction with conventional vasodilator stress agents. Regadenoson, a selective $\mathrm{A}_{2 \mathrm{~A}}$ adenosine receptor agonist, has gained popularity due to its ease of administration and improved patient experience in the general population. The literature describing the experience with regadenoson in COPD patients, though limited, is rapidly growing and reassuring. This review summarizes the pharmacology and clinical application of this novel stress agent and presents the available data on the safety and tolerability of its use in COPD patients.
\end{abstract}

Keywords: chronic obstructive pulmonary disease, COPD, regadenoson, myocardial perfusion imaging, safety, tolerability, asthma, emphysema

\section{Introduction}

Since chronic obstructive pulmonary disease (COPD) and coronary artery disease have overlapping symptoms and share the risk factor of cigarette smoking, it is not uncommon for COPD patients to undergo cardiac stress testing. A contemporary study found that approximately $30 \%$ of patients undergoing adenosine myocardial perfusion imaging (MPI) for the evaluation of ischemic heart disease had a diagnosis of COPD based on medical history alone. ${ }^{1}$ However, stress testing in COPD patients poses a particular challenge. First, patients' compromised functional capacity due to underlying lung disease tends to be an impediment to reaching an adequate exercise level; this limitation leaves most practitioners with the option of using pharmacologic stress agents as an adjunct to echocardiographic or MPI modalities. Furthermore, these patients tend to have poor acoustic windows due to emphysematous changes that impair the quality and therefore diagnostic accuracy of stress echocardiography techniques. Thus, from the imaging perspective, MPI with single-photon emission computed tomography or positron emission tomography is an attractive alternative. The preferred pharmacologic stress agents with MPI are coronary vasodilators in the form of direct or indirect adenosine agonists. ${ }^{2,3}$ However, due to a concern for adenosineinduced bronchoconstriction, the conventional vasodilator stress agents, adenosine and dipyridamole, are contraindicated in patients with bronchospastic disease and are to be "used with caution" in patients with COPD. ${ }^{2,4}$ Dobutamine, a beta-receptor agonist, 
is considered safe in COPD patients. Unfortunately, it is less effective at increasing coronary blood flow, associated with a higher incidence of adverse events, requires more time for protocol completion, and is therefore considered an inferior MPI stress agent. ${ }^{3,5-7}$

The US Food and Drug Administration's 2008 approval of regadenoson, a selective $\mathrm{A}_{2 \mathrm{~A}}$ adenosine receptor agonist, as a vasodilator stress agent has shifted the landscape of vasodilator MPI. In a short timeframe, regadenoson has become the vasodilator of choice in approximately $80 \%$ of stress laboratories in the USA. ${ }^{8}$ Not only has its fixed (weight-unadjusted) bolus dosing, short half-life, and safety profile added to its popularity, but also phase III clinical trials showed that patients reported a more favorable experience when compared with adenosine. ${ }^{9-11}$ How far the improved safety and tolerability of regadenoson can be extrapolated to COPD and asthma patients is not readily defined. Less than $10 \%$ of patients included in the phase III trials studying regadenoson had COPD or asthma, and clinical trial participants tend to be healthier than the general patient population referred for myocardial MPI. ${ }^{12}$ Furthermore, post-marketing experience has reported respiratory arrest, dyspnea, and wheezing following regadenoson administration, and the package insert for regadenoson (Lexiscan ${ }^{\circledR}$ in the USA [Astellas Pharma US; Northbrook, IL, USA] and Rapiscan ${ }^{\circledR}$ in Europe [Rapidscan Pharma Solutions EU Ltd; London, UK]) instructs practitioners to "use with caution" in patients with COPD and asthma. ${ }^{4}$ Also, since the concern for severe bronchospastic reactions associated with other vasodilator agents is in recent memory, the use of regadenoson in this patient population is met with some apprehension. ${ }^{13}$ The aim of this review is to present the pharmacology and clinical use of regadenoson and to review available data on the safety and tolerability of its use in COPD patients.

\section{Regadenoson as a vasodilator stress agent}

Vasodilator stress MPI detection of coronary artery disease is based on the heterogeneity of radioisotope uptake in myocardium being supplied by significantly diseased versus non-diseased coronary arteries. With the administration of vasodilator agents, normal coronary arteries have a three- to five-fold augmentation of myocardial blood flow (MBF), while coronary arteries with fixed stenoses have limited increases in MBF. ${ }^{14}$ The disparity in coronary blood flow between normal and diseased coronary arteries leads to nonhomogeneity in radioisotope uptake between the myocardial territories supplied by these arteries, resulting in perfusion defects detected by a scintillation camera. ${ }^{14}$

One of the main functions of adenosine, an endogenous substance found in all cells, is to regulate blood flow in various vascular beds. All vasodilator stress agents used with MPI act as direct (regadenoson and adenosine) or indirect (dipyridamole) agonists of the adenosine receptor, of which

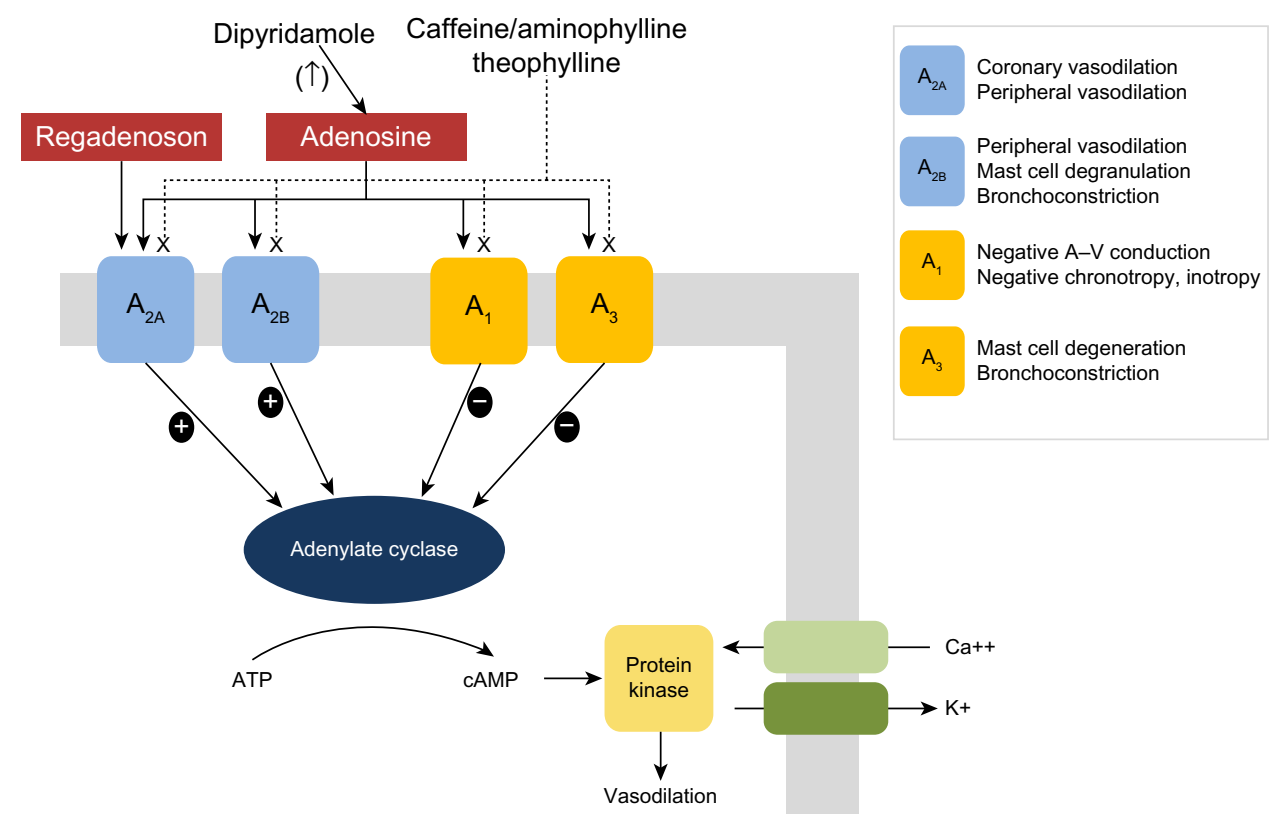

Figure I Adenosine receptor subtypes, mechanisms of action, and clinical effects.

Note: Springer and J Nucl Cardiol, 17, 2010, 494-497, The emerging role of the selective A2A agonist in pharmacologic stress testing, Gemignani AS, Abbott BG, Figure I.23 With kind permission from Springer Science and Business Media.

Abbreviations: ATP, adenosine triphosphate; cAMP, cyclic adenosine monophosphate. 
there are four subtypes: $A_{1}, A_{2 A}, A_{2 B}$, and $A_{3}$ (Figure 1). For the purposes of vasodilator stress MPI, the desired effect of coronary vasodilation is mediated primarily, but not exclusively, through activation of the $\mathrm{A}_{2 \mathrm{~A}}$ receptors found in the coronary vascular wall. Receptor agonism stimulates adenylate cyclase causing an increase in production of cyclic adenosine monophosphate, which results in decreased sarcolemmic calcium uptake and subsequent smooth muscle relaxation. ${ }^{15-17}$ However, the undesired effects of these agents result from the fact that all adenosine agonists activate, to different degrees, other adenosine receptor subtypes at recommended clinical doses, which can result in atrioventricular block ( $\mathrm{A}_{1}$ receptor), peripheral vasodilation $\left(\mathrm{A}_{2 \mathrm{~B}}\right.$ receptor), and bronchoconstriction due to mast cell degranulation and immunoglobulin $\mathrm{E}$ and histamine release $\left(\mathrm{A}_{2 \mathrm{~B}}\right.$ and $\mathrm{A}_{3}$ receptors), as shown in Figure 1.,18

Regadenoson, in preliminary in vitro and animal studies, exhibited high $\mathrm{A}_{2 \mathrm{~A}}$ receptor selectivity and potency but low affinity, all properties of an ideal vasodilator stress agent. Regadenoson is 100 times more potent than adenosine at the $A_{2 \mathrm{~A}}$ receptor and has a greater affinity and selectivity at the $\mathrm{A}_{2 \mathrm{~A}}$ receptor site than the other adenosine receptor subtypes. ${ }^{14,17,19}$ Gao et $\mathrm{a}^{20}$ found that regadenoson has an affinity at the $\mathrm{A}_{2 \mathrm{~A}}$ receptor that is 13 times higher than its affinity at the $A_{1}$ receptor, which manifests in its ability to induce coronary vasodilation $\left(\mathrm{A}_{2 \mathrm{~A}}\right.$ receptor) without slowing conduction through the atrioventricular node $\left(\mathrm{A}_{1}\right.$ receptor $)$ in isolated rat hearts. Furthermore, regadenoson has minimal activity at the $\mathrm{A}_{2 \mathrm{~B}}$ and $\mathrm{A}_{3}$ receptors, the sites responsible for adenosine-induced bronchoconstriction. ${ }^{20}$ Regadenoson also exhibits low receptor affinity, defined as the ratio of the rate of drug dissociation to the rate of drug association. In a vascular bed with a large receptor reserve such as the coronary arteries, this property allows regadenoson to exert potent and rapid vasodilation while having a short duration of action. . $^{14,19,20}$ Notably, the advantageous features of regadenoson are not at the expense of impaired vasodilatory ability when compared with adenosine. Two preliminary studies using dog models showed that an intravenous bolus of regadenoson was comparable to an intravenous infusion of adenosine in causing a dose-dependent decrease in coronary vascular resistance and increase in MBF, with the effect lasting longer in the regadenoson group (97 versus [vs] 24 seconds; $P<0.01$ ). ${ }^{16,17}$

These promising preliminary findings were confirmed in the clinical setting in phase III, Adenosine versus Regadenoson Comparative Evaluation in Myocardial Perfusion Imaging (ADVANCE MPI) trials ( 1 and 2), which were designed as randomized, double-blinded, non-inferiority studies enrolling more than 2,000 patients from over 100 sites. ${ }^{10,11,21}$ The results demonstrated that regadenoson was non-inferior to adenosine in the detection of myocardial ischemia for all patients while having improved overall tolerability. Of note, both regadenoson and adenosine groups were similar in their reporting of subjective dyspnea ( $28 \%$ vs $26 \%$ ), and the regadenoson group actually reported more headache and gastrointestinal discomfort but fewer symptoms of flushing. However, the regadenoson group had lower combined symptom scores and reported a more favorable experience than the adenosine group. ${ }^{21}$ The findings of these pivotal trials led to the approval of regadenoson as a vasodilator stress agent in April 2008 in the USA and subsequently in Europe in September 2010.

\section{Pharmacokinetics}

Regadenoson is a 2-[N-1-(4-N-methylcarboxamidopyrazolyl)] pyrazole adenosine derivative (Figure 2). ${ }^{22} \mathrm{It}$ is administered as a single $400 \mathrm{mcg}$ intravenous bolus dose delivered over 10 seconds followed by a $5 \mathrm{~mL}$ saline flush. The radiotracer is administered 30 seconds after the regadenoson bolus. ${ }^{23}$

Regadenoson can be administered as an intravenous bolus rather than a continuous infusion because, unlike adenosine, it is not metabolized by the cell membrane nucleoside transporter or by the plasma adenosine deaminase. ${ }^{24}$ The pharmacokinetics of regadenoson follows a three-compartment model. ${ }^{25}$ The maximal plasma concentration of regadenoson is achieved within 1-4 minutes after intravenous bolus injection; the half-life of this initial phase of the onset of pharmacodynamic response is approximately $2-4$ minutes. The subsequent intermediate phase has an average half-life of 30 minutes, during which the pharmacodynamic effect is lost. The plasma concentration declines during the terminal phase, which has a half-life of approximately 2 hours. ${ }^{25}$

The central compartment volume of distribution is $11.5 \mathrm{~L}$, and the steady state volume of distribution is $78.7 \mathrm{~L}$

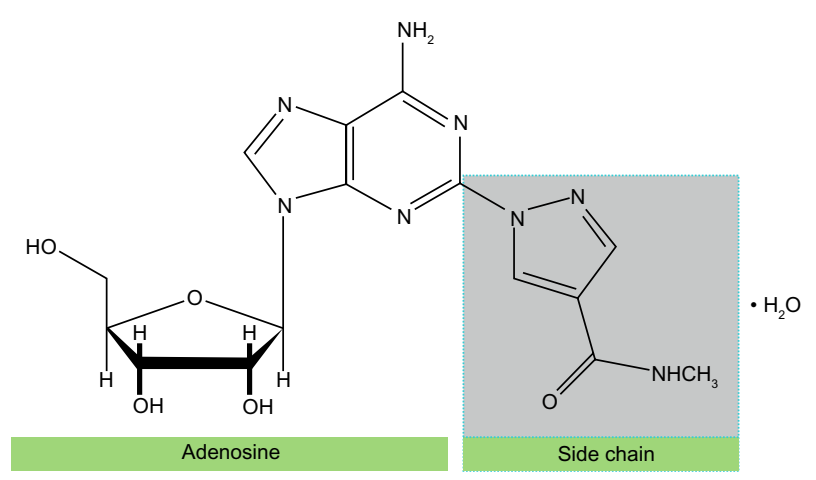

Figure 2 Regadenoson molecule.

Note: Reproduced with permission from Astellas Pharma; US Lexiscan Product Monograph. 2012.22 
with an estimated clearance of $37.8 \mathrm{~L} / \mathrm{h} .{ }^{14}$ Regadenoson's volume of distribution, terminal half-life, and excretion are dose independent. Renal excretion accounts for $58 \%$ of total regadenoson elimination. ${ }^{25,26}$ Though decreasing renal function prolongs the elimination half-life of a single intravenous bolus of $400 \mathrm{mcg}$ of regadenoson, its maximal plasma concentration and severity and number of adverse side effects are not affected significantly. ${ }^{14}$ Therefore, dose adjustments are unnecessary in patients with impaired renal function, and regadenoson has been shown to be safe in patients with chronic kidney disease, including those with end-stage renal disease on hemodialysis. ${ }^{14,27-30}$

\section{Safety and tolerability of regadenoson in COPD patients}

Two pilot studies were conducted to investigate the safety of regadenoson in COPD and asthma patients. ${ }^{1,31}$ The RegCOPD study was a randomized, double-blinded, placebo-controlled, crossover trial in which patients with moderate $(n=38)$ or severe ( $n=11)$ COPD were studied. ${ }^{1}$ At baseline, these patients had significantly compromised lung function, with $37 \%$ of patients having dyspnea during activities of daily living. Notably, patients receiving glucocorticoids or oxygen and those with pretreatment wheezing were included. Short-acting bronchodilators were withheld for at least 8 hours before the stress study. There were no differences between regadenoson and placebo on repeated measurements of forced expiratory volume in 1 second $\left(\mathrm{FEV}_{1}\right)$, forced vital capacity (FVC), respiratory rate, pulmonary examinations, and oxygen saturation at pre-specified time intervals up to 120 minutes postregadenoson or placebo administration. The mean maximum decline in $\mathrm{FEV}_{1}$ was $0.11 \pm 0.02 \mathrm{~L}$ and $0.12 \pm 0.02 \mathrm{~L}(P=0.55)$ in the regadenoson and placebo groups, respectively. Figure 3 illustrates the changes in $\mathrm{FEV}_{1}$ and $\mathrm{FVC}$ in patients who received regadenoson versus placebo. New-onset wheezing was noted in $6 \%$ and $12 \%$ of the regadenoson and placebo groups, respectively $(P=0.33)$. Bronchoconstrictive reactions, defined as a $>15 \%$ reduction in $\mathrm{FEV}_{1}$ from baseline, were clinically silent and occurred in $12.2 \%$ and $6.1 \%$ of the regadenoson and placebo groups, respectively $(P=0.31)$. Dyspnea was reported in $61 \%$ of patients in the regadenoson group and in $0 \%$ of patients in the placebo group and was not related to a decline in $\mathrm{FEV}_{1}$ or other objective findings. No patient required treatment with bronchodilators or oxygen. ${ }^{1}$ Similarly, in the RegAsthma study, a randomized, doubleblinded, placebo-controlled, crossover study of 48 subjects with mild or moderate asthma who demonstrated bronchial reactivity to adenosine monophosphate, Leaker et $\mathrm{al}^{31}$ found that mean $\mathrm{FEV}_{1}$ in the regadenoson group was not statistically different from the placebo group at any of the scheduled assessments up to 120 minutes post-dose. There was no statistically significant difference in quantitative bronchoconstrictive reactions experienced between study and placebo groups. Furthermore, bronchoconstrictive reactions observed were not associated with pulmonary adverse events, serious adverse events, or study termination. ${ }^{31}$ These two pilot studies demonstrated the overall safety of regadenoson in clinically stable patients with mild to moderate asthma and moderate to severe COPD, thus clinically supporting the hypothesis that regadenoson does not elicit bronchoreactivity due to its selective action on the $\mathrm{A}_{2 \mathrm{~A}}$ receptor. ${ }^{1}$

Following the results of these small pilot studies, Husain et $\mathrm{al}^{32}$ attempted to assess the safety of regadenoson in a larger number of unselected patients with underlying lung disease. In this retrospective study of consecutive patients referred for clinically indicated regadenoson stress MPI, the authors identified 228 patients with COPD $(n=126)$ and asthma $(n=102)$ and compared them with 1,142 consecutive patients without underlying lung disease. Patient outcomes were defined as any COPD or asthma exacerbations leading to treatment, hospitalization, or death at 24 hours and 1 week after regadenoson administration based on electronic medical record documentation. According to these definitions, there was $0 \%$ incidence of clinical exacerbation of COPD or asthma after regadenoson MPI. COPD patients had more non-significant arrhythmias $(58.3 \%$ vs $43 \% ; P=0.004)$ than patients without COPD or asthma, but the majority of these arrhythmias were premature atrial and/or ventricular complexes, with only two brief self-terminating episodes of supraventricular tachycardia. There was $0 \%$ incidence of any atrioventricular block. ${ }^{32}$ While these findings are consistent with data from the pilot studies, they should be weighed with the limitations that are inherent in identifying adverse events by chart review. While some patients in the COPD or asthma group had documented pulmonary function tests consistent with these diagnoses, self-declaration of COPD or asthma history was alone sufficient to be included in the study group. Furthermore, severity of COPD/asthma was not defined, and adverse outcomes were noted only if they were severe enough to have warranted a documented clinical encounter or death. Though the study cohort was described as comprising unselected, consecutive patients with COPD or asthma undergoing regadenoson stress MPI, these patients were, in effect, preselected by practitioners who deemed their underlying lung disease stable enough for regadenoson to be safely administered. 


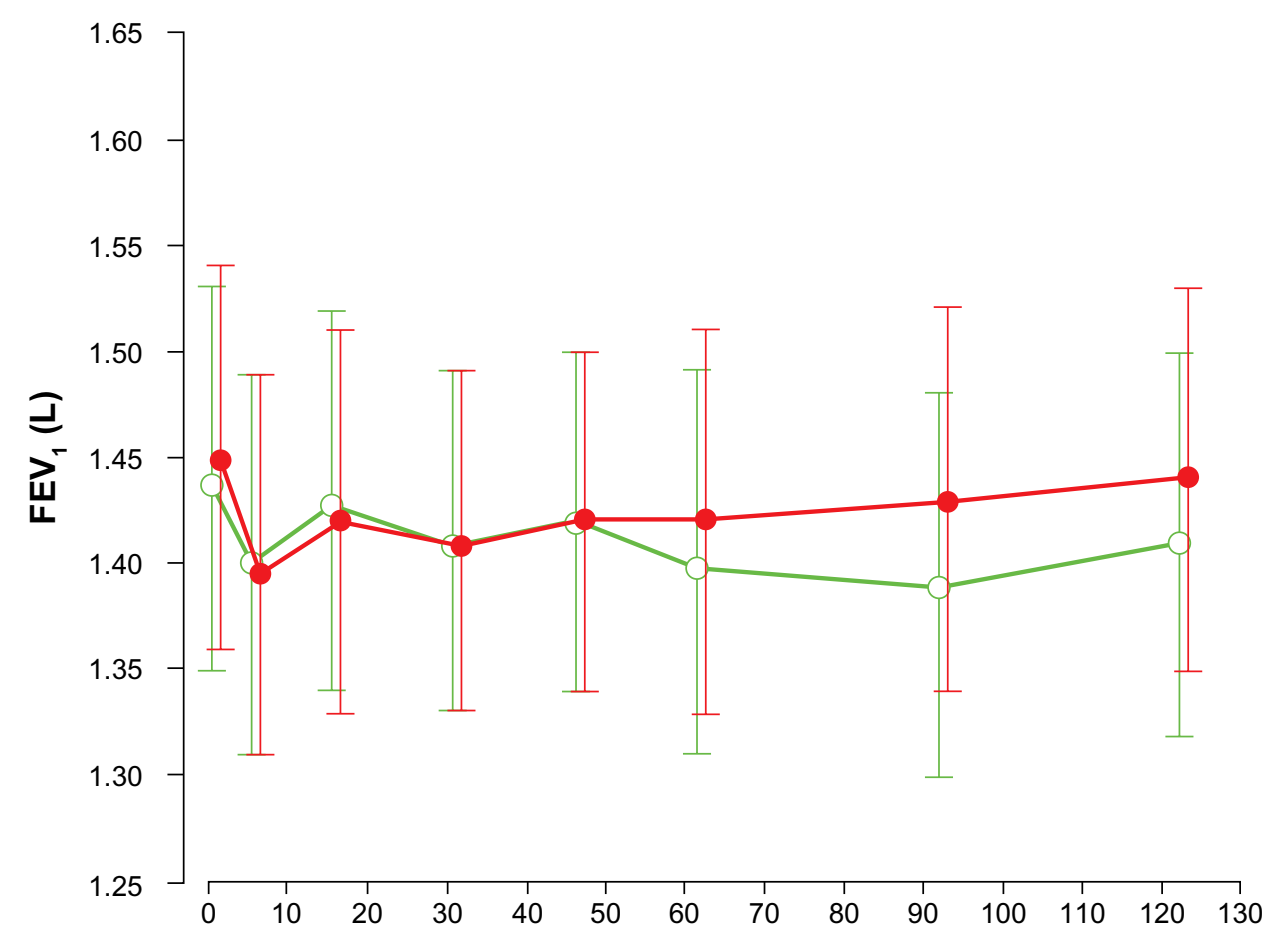

\section{Time (minutes)}

\section{Study drug}
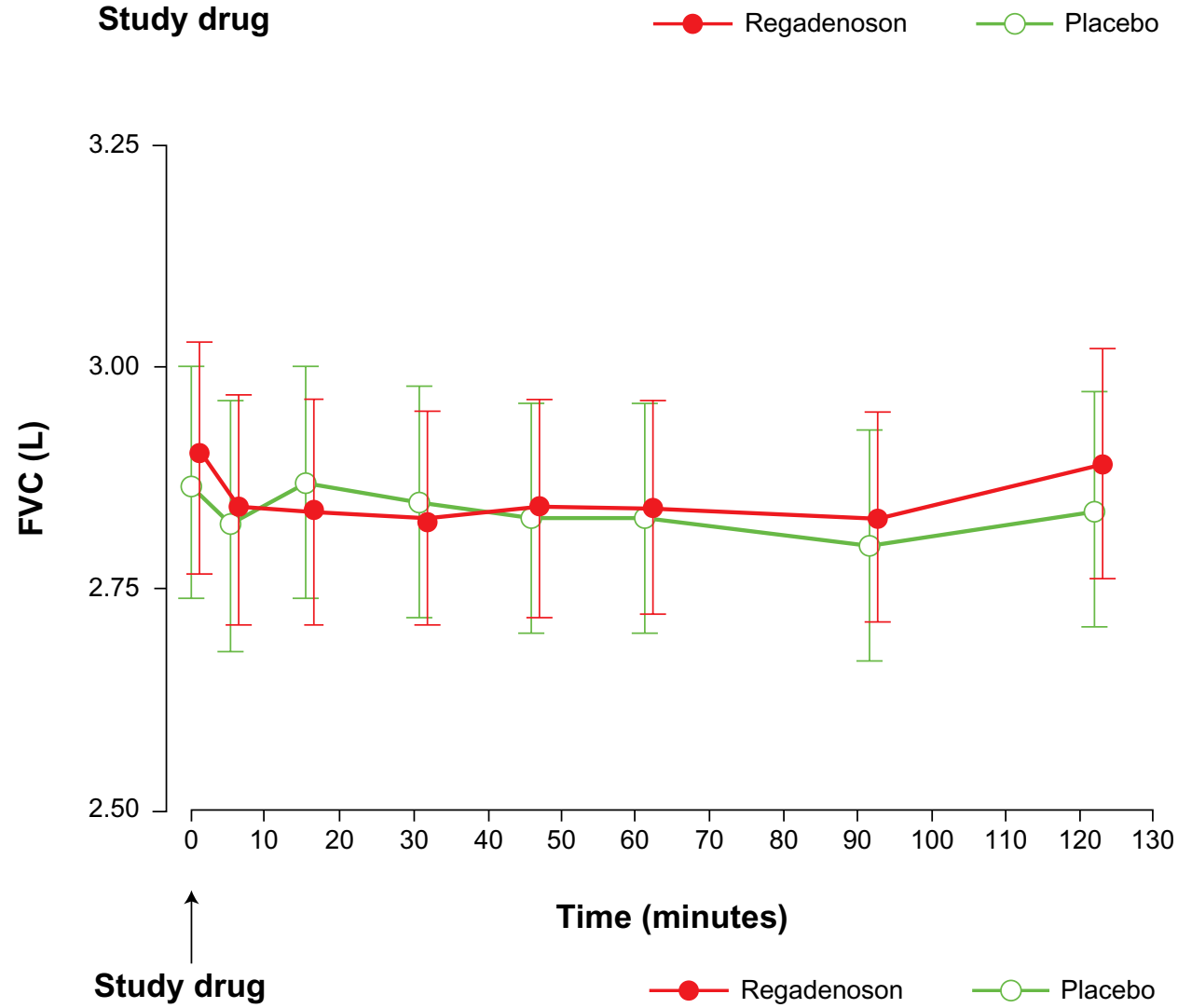

Figure 3 Mean FEV, and mean FVC changes following regadenoson.

Notes: For comparison of regadenoson and placebo for all time points, data are expressed as least squares mean \pm standard error $(P \geq 0.074$ and $P>0.28$, respectively). The regadenoson curve is staggered slightly to the right to improve visualization of both sets of error bars. Springer and J Nucl Cardiol, I5, 2008, 319-328, Safety of regadenoson, a selective adenosine A2A agonist, in patients with chronic obstructive pulmonary disease: a randomized, double-blind, placebo-controlled trial (RegCOPD trial), Thomas GS, Tammelin BR, Schiffman GL, et al, Figures 2 and 3.' With kind permission from Springer Science and Business Media.

Abbreviations: $\mathrm{FEV}_{1}$, forced expiratory volume in I second; FVC, forced vital capacity. 
Although the retrospective study by Husain et al ${ }^{32}$ reported including some patients who performed adjunctive low-level exercise when possible, they did not report the experiences of these patients separately. Combination testing with low-level exercise $(1.7 \mathrm{mph}, 0 \%$ grade) is recommended by the American Society of Nuclear Cardiology practice guidelines based on data that has shown that low-level exercise during adenosine MPI appears to decrease adverse effects, improve patient acceptance and image quality, and may increase the sensitivity for detecting perfusion defects. ${ }^{33,34}$ In order to further investigate the role of combination testing in patients with underlying lung disease, Garcia et $\mathrm{al}^{5}$ conducted an observational study of 116 unselected patients with mild/moderate COPD ( $n=67)$ or asthma ( $\mathrm{n}=49$ ) who underwent pharmacologic stress MPI with regadenoson in combination with low-level treadmill exercise. There was a higher incidence of dyspnea in COPD than in asthma patients $(40.3 \%$ vs $22.4 \% ; P<0.05)$, while asthma patients reported more headache and feeling hot ( $6 \%$ vs $18.4 \%$ and $10.4 \%$ vs $26.5 \%$, respectively; $P<0.05$ ). Adverse events were self-limited, except in three patients who suffered persistent dyspnea ( 2 of 67 COPD patients; 1 of 49 asthma patients) requiring theophylline administration. ${ }^{5} \mathrm{Of}$ note, the inclusion of COPD or asthma patients was based on medical history, and patients with severe COPD/asthma or active bronchoconstriction based on physical exam were excluded. The study demonstrated the feasibility of combined low-level exercise in patients with COPD or asthma and suggested that the frequency of dyspnea with this stress technique was similar to other published series without adjunctive low-level exercise. Few other conclusions can be drawn from this study regarding the role of regadenoson stress with low-level exercise in patients with COPD/asthma since the study cohort was not compared with patients who did not participate in low-level exercise or those who did not have underlying lung disease.

Additional information regarding regadenoson stress with low-level exercise can be drawn from a subgroup analyses of a study by Kwon et al ${ }^{12}$ who analyzed data from 1,263 patients who underwent clinically indicated MPI with regadenoson with $(\mathrm{n}=596)$ and without $(\mathrm{n}=667)$ low-level exercise. Of these patients, 105 had COPD and 96 had asthma. Other than the fact that patients with active wheezing were excluded, the severity of underlying lung disease was not defined, and inclusion was based on medical history alone. In the entire study population, the most frequently reported symptoms were chest pain (35\%) and dyspnea (27\%), and COPD/ asthma patients experienced dyspnea at a rate similar to that of their counterparts without lung disease. ${ }^{12}$ Participants who underwent low-level treadmill testing were significantly less likely to report symptoms of dyspnea ( $23 \%$ vs $32 \%$; $P=0.009)$, though results were not reported separately for COPD/asthma patients. Of note, there were fewer COPD patients in the low-level treadmill group, and generally, the patients who were able to participate in low-level exercise were younger and had fewer co-morbidities which could have contributed to their experiencing fewer adverse events. Due to the limited data available from these two studies, the question as to whether the addition of low-level exercise could attenuate the adverse effects of regadenoson in COPD patients remains unanswered. ${ }^{12}$

Further inference regarding the safety and tolerability of regadenoson stress in patients with COPD and asthma can be drawn from the Attenuation of the Side Effect Profile of Regadenoson with Aminophylline in Patients Undergoing Myocardial Perfusion Imaging (ASSUAGE and ASSUAGECKD) trials by Doukky et al. ${ }^{27,28}$ These were double-blinded, placebo-controlled clinical trials that evaluated the efficacy of intravenous administration of $75 \mathrm{mg}$ of aminophylline (adenosine receptor antagonist) versus placebo injected approximately 2 minutes following regadenoson stress in reducing the incidence and severity of regadenoson-related adverse effects. The trials were identical in their design, methods, and inclusion and exclusion criteria, except that the ASSUAGE-CKD trial $(\mathrm{n}=300)$ was limited to patients with glomerular filtration rate $<30 \mathrm{~mL} / \mathrm{min} / 1.73 \mathrm{~m}^{2}$ (chronic kidney disease stage 4,5 , and end-stage renal disease), while the ASSUAGE trial $(n=248)$ was open for all-comers regardless of kidney function. ${ }^{27,28}$ The pooled database of both trials ( $\mathrm{n}=548)$ included 67 (12\%) patients with COPD $(n=23)$ or asthma $(n=44) \cdot{ }^{27,28}$ Notably, the patients enrolled in these trials were referred for clinically indicated MPI, thus they were deemed to be appropriate for regadenoson stress by their physicians. Although these studies were not primarily designed to investigate the effect of regadenoson in patients with COPD/asthma, dyspnea and bronchospasm were predefined endpoints in these trials and documented prospectively at the end of the stress MPI encounter and again 24 hours later. In the pooled database of both trials, the incidence of dyspnea among the 67 patients with COPD/asthma had a slightly higher trend than those without COPD/asthma but was not statistically different between patients with and those without COPD/asthma ( $12 \%$ vs $8 \%$; $P=0.49)$. Moreover, none of the patients with or without COPD/asthma in these trials had bronchospastic events requiring treatment with bronchodilators or non-protocol 
intravenous aminophylline. Patients with COPD/asthma who were randomized to receive aminophylline had fewer events of dyspnea than those who received placebo (12\% vs $20 \%)$, but the difference was not statistically significant $(P=0.39)$. Also, among patients with COPD/asthma, the incidence of dyspnea was not increased among patients with versus without end-stage renal disease $(P=0.21)$. These analyses were performed solely for the purpose of this review and were not reported in the original reports from these trials. ${ }^{27,28}$ It is important to note that the COPD/asthma subgroup in the ASSUAGE and ASSUAGE-CKD trials is underpowered to draw definitive conclusions regarding the safety and tolerability of regadenoson. However, these data support findings from other published reports presented in this review. Additionally, despite an apparent trend, these trials are not sufficiently powered to determine whether aminophylline administration following regadenoson can improve tolerability among patients with COPD/asthma. This question remains open for future research.

Though the results of these pilot trials, observational studies, and subgroup analyses from larger trials are promising regarding the safety and tolerability of regadenoson in COPD and asthma patients, there has been only one phase IV clinical trial that has addressed this question. Prenner et $\mathrm{al}^{18}$ conducted a prospective, randomized, double-blinded, placebo-controlled trial assessing the safety of regadenoson

Table I Studies evaluating safety and tolerability of regadenoson in chronic obstructive pulmonary disease/asthma patients

\begin{tabular}{|c|c|c|c|c|}
\hline Study & Design & $\begin{array}{l}\text { Severity/type of lung } \\
\text { disease }^{a}\end{array}$ & $\begin{array}{l}\text { Respiratory } \\
\text { parameters }\end{array}$ & Conclusion \\
\hline Thomas et al' & $\begin{array}{l}\text { Prospective, randomized, } \\
\text { double-blinded, placebo- } \\
\text { controlled, crossover }\end{array}$ & $\begin{array}{l}\text { Moderate COPD, } \mathrm{n}=38 \\
\text { Severe COPD, } \mathrm{n}=\mathrm{II}\end{array}$ & $\begin{array}{l}\mathrm{FEV}_{1}, \mathrm{FVC}, \mathrm{RR}, \mathrm{O}_{2} \\
\text { saturation, pulmonary } \\
\text { examinations }\end{array}$ & $\begin{array}{l}\text { Subjective dyspnea more common } \\
\text { with regadenoson } \\
\text { No significant decline in } \mathrm{FEV}_{1} \\
\text { or other objective spirometric } \\
\text { parameters }\end{array}$ \\
\hline Leaker et $\mathrm{a}^{31}$ & $\begin{array}{l}\text { Prospective randomized, } \\
\text { double-blinded, placebo- } \\
\text { controlled, crossover }\end{array}$ & $\begin{array}{l}\text { Mild/moderate asthma, } \\
\mathrm{n}=48\end{array}$ & $\mathrm{FEV}_{\text {, }}$ & $\begin{array}{l}\text { No difference in quantitative } \\
\text { bronchoconstrictive } \\
\text { parameters between } \\
\text { regadenoson and placebo }\end{array}$ \\
\hline Husain et $\mathrm{al}^{32}$ & Retrospective & $\begin{array}{l}\text { COPD, } n=126 \\
\text { Asthma, } n=102\end{array}$ & $\begin{array}{l}\text { Exacerbations } \\
\text { leading to treatment, } \\
\text { hospitalization, or death }\end{array}$ & $\begin{array}{l}\text { No events of clinical } \\
\text { exacerbation at } 24 \text { hours and } \\
\text { I week after regadenoson }\end{array}$ \\
\hline Garcia et $\mathrm{al}^{5}$ & $\begin{array}{l}\text { Prospective, observational } \\
\text { (regadenoson }+ \text { low-level } \\
\text { exercise) }\end{array}$ & $\begin{array}{l}\text { Mild/moderate COPD, } \\
\mathrm{n}=67 \\
\text { Asthma, } \mathrm{n}=49\end{array}$ & Reported symptoms & $\begin{array}{l}\text { COPD patients experienced more } \\
\text { dyspnea than asthma patients } \\
\text { Frequency of subjective dyspnea } \\
\text { was similar to other published } \\
\text { studies without adjunctive low- } \\
\text { level exercise }\end{array}$ \\
\hline Kwon et al' ${ }^{12}$ & $\begin{array}{l}\text { Prospective, observational } \\
\text { (regadenoson + low-level } \\
\text { exercise) }\end{array}$ & $\begin{array}{l}\text { COPD, } \mathrm{n}=105 \\
\text { Asthma, } \mathrm{n}=96\end{array}$ & Reported symptoms & $\begin{array}{l}\text { Less dyspnea reported with } \\
\text { patients who underwent adjunctive } \\
\text { low-level exercise }\end{array}$ \\
\hline Doukky et $\mathrm{al}^{27,28}$ & $\begin{array}{l}\text { Prospective, randomized, } \\
\text { double-blinded, } \\
\text { aminophylline versus placebo } \\
\text { following regadenoson }\end{array}$ & $\begin{array}{l}\text { COPD, } n=23 \\
\text { Asthma, } n=44\end{array}$ & $\begin{array}{l}\text { Reported symptoms, } \\
\text { clinical bronchospasm, } \\
\text { hospitalization }\end{array}$ & $\begin{array}{l}\text { No significant difference in reported } \\
\text { dyspnea between COPD/asthma } \\
\text { patients and those without lung } \\
\text { disease or in COPD/asthma } \\
\text { patients with or without ESRD } \\
\text { No reported bronchospastic } \\
\text { reactions }\end{array}$ \\
\hline Prenner et $\mathrm{al}^{18}$ & $\begin{array}{l}\text { Prospective, randomized, } \\
\text { double-blinded, placebo- } \\
\text { controlled }\end{array}$ & $\begin{array}{l}\text { COPD, }{ }^{b} n=316 \\
\text { Asthma, }{ }^{c} n=356\end{array}$ & $\begin{array}{l}\mathrm{FEV}_{1}, \mathrm{FVC}, \mathrm{FEV}_{1} / \mathrm{FVC}, \mathrm{O}_{2} \\
\text { saturation }\end{array}$ & $\begin{array}{l}\text { Subjective dyspnea was more } \\
\text { common in the regadenoson group } \\
\text { No significant decline in FEV } \\
\text { or other objective spirometric } \\
\text { parameters }\end{array}$ \\
\hline
\end{tabular}

Notes: ${ }^{N}$ Number of patients with underlying lung disease who received regadenoson; ${ }^{b} \mathrm{FEV} / \mathrm{FVC}<0.7$; ' reasonably well-controlled asthma (FEV $\geq 60 \%$ predicted), unchanged symptom frequency and severity within the prior 30 days.

Abbreviations: COPD, chronic obstructive pulmonary disease; ESRD, end-stage renal disease; FEV ${ }_{1}$, forced expiratory volume in I second; FVC, forced vital capacity; $R R$, respiratory rate. 
in subjects with COPD or asthma. COPD was defined by an $\mathrm{FEV}_{1} / \mathrm{FVC}$ ratio $<0.70$; though patients from all severity strata were included, the state of their underlying lung disease had to be relatively stable. The frequency and severity of symptoms had to be unchanged within 30 days prior to the study, and asthmatic subjects had to have an $\mathrm{FEV}_{1} \geq 60 \%$ predicted. A total of 999 patients with coronary disease or risk factors were randomized to receive regadenoson $(n=672)$ or placebo in a 2:1 fashion with subsequent serial pulmonary function tests and clinical assessment at predefined time intervals up to 24 hours after study drug administration. The rate of bronchoconstriction, defined as a $>15 \%$ decrease in $\mathrm{FEV}_{1}$, from baseline to any post-baseline assessment up to 24 hours after regadenoson administration was not statistically significantly different between the regadenoson and the placebo groups in the asthma or COPD subgroups, regardless of severity. Other pulmonary function parameters such as $\mathrm{FVC}, \mathrm{FEV}_{1} / \mathrm{FVC}$, and arterial oxygen saturation also did not differ between the study groups. The most frequently reported adverse respiratory event was dyspnea, which occurred with higher incidence in the regadenoson than the placebo group, in both asthma (10.7\% vs $1.1 \%)$ and COPD (18.0\% vs $2.6 \%)$ subgroups $(P<0.0001)$. No subjects experienced severe bronchoconstriction, and only one regadenoson patient received aminophylline for bronchospasm. ${ }^{18}$ Notably, although the study cohort represents a wide range of asthma and COPD severity, only participants with stable lung disease, without any medication changes or exacerbations within 1 month prior to study drug administration, were included. The findings of this study are consistent with the conclusions of the RegCOPD and RegAsthma pilot studies, suggesting that although COPD and asthma patients may have a higher incidence of subjective dyspnea, this does not correlate with quantitatively defined bronchoconstriction.

\section{Discussion}

While regadenoson has become the vasodilator stress agent of choice and has streamlined and simplified stress protocols in many nuclear stress laboratories, the adverse effect of dyspnea is still experienced by many patients, and even more so by those with COPD and asthma. While patients and practitioners should anticipate this symptom, several studies have shown that the subjective experience of dyspnea is not correlated with and is not caused by bronchoconstriction. Available data from observational studies as well as controlled clinical trials, as summarized in Table 1, indicate that the use of regadenoson in patients with mild to moderate asthma and mild to moderate COPD is safe. The current data in patients with severe COPD, while limited, are reassuring and indicate that regadenoson is probably safe, particularly in those with stable lung disease. Clinical data are limited in COPD patients who require 24-hour/day home oxygen administration, have previously been intubated for respiratory failure, or have had recent exacerbations or required uptitration of their medication regimen within a 1-month period; regadenoson should therefore be used with caution in this patient population. Similarly, regadenoson has not been studied in patients with severe bronchial asthma $\left(\mathrm{FEV}_{1}<60 \%\right)$; thus, it should be avoided in these patients at this time.

\section{Potential targets for future research}

Additional data from larger cohorts with severe COPD are certainly needed. The question as to whether low-level exercise or intravenous aminophylline could attenuate the adverse effects of regadenoson in COPD patients remains unanswered and constitutes great grounds for future research.

\section{Conclusion}

Regadenoson pharmacologic stress for MPI has been demonstrated to be safe to use in patients with mild to moderate COPD and asthma. Regadenoson should be used with caution in COPD patients with a 24-hour/day home oxygen requirement, prior intubation for respiratory failure, or recent exacerbation. Regadenoson should be avoided in patients with severe bronchial asthma at this time.

\section{Disclosure}

Dr Rami Doukky received research funding from Astellas Pharma and has served on the advisory board of Astellas Pharma. Dr Yasmeen Golzar has no conflicts to declare.

\section{References}

1. Thomas GS, Tammelin BR, Schiffman GL, et al. Safety of regadenoson, a selective adenosine $\mathrm{A} 2 \mathrm{~A}$ agonist, in patients with chronic obstructive pulmonary disease: a randomized, double-blind, placebo-controlled trial (RegCOPD trial). J Nucl Cardiol. 2008;15(3):319-328.

2. Doukky R. Pharmacologic stress testing in myocardial perfusion imaging: technical applications. In: Heller GV, Mann A, Hendel RC, editors. Nuclear Cardiology: Technical Applications. New York: McGraw-Hill; 2007:107-124.

3. Wu JC, Yun JJ, Heller EN, et al. Limitations of dobutamine for enhancing flow heterogeneity in the presence of single coronary stenosis: implications for technetium-99m-sestamibi imaging. $J$ Nucl Med. 1998;39(3):417-425.

4. Lexiscan ${ }^{\circledR}$ (regadenoson) injection for intravenous use [package insert]. Northbrook, IL: Astellas Pharma US; 2013.

5. Garcia C, Heffernan AJ, Sanchez de Mora E, et al. Comparative study of the safety of regadenoson between patients with mild/moderate chronic obstructive pulmonary disease and asthma. Eur J Nucl Med Mol Imaging. 2014;41(1):119-125.

6. Geleijnse ML, Elhendy A, Fioretti PM, Roelandt JR. Dobutamine stress myocardial perfusion imaging. J Am Coll Cardiol. 2000;36(7): 2017-2027. 
7. Geleijnse ML, Fioretti PM, Roelandt JR. Methodology, feasibility, safety and diagnostic accuracy of dobutamine stress echocardiography. $J \mathrm{Am}$ Coll Cardiol. 1997;30(3):595-606.

8. AMR/Arlington Medical Resources Inc. Myocardial Perfusion Monthly Monitor, Nov 2012.

9. Ghimire G, Hage FG, Heo J, Iskandrian AE. Regadenoson: a focused update. J Nucl Cardiol. 2013;20(2):284-288.

10. Iskandrian AE, Bateman TM, Belardinelli L, et al; ADVANCE MPI Investigators. Adenosine versus regadenoson comparative evaluation in myocardial perfusion imaging: results of the ADVANCE phase 3 multicenter international trial. J Nucl Cardiol. 2007;14(5):645-658.

11. Mahmarian JJ, Cerqueira MD, Iskandrian AE, et al. Regadenoson induces comparable left ventricular perfusion defects as adenosine: a quantitative analysis from the ADVANCE MPI 2 trial. JACC Cardiovasc Imaging. 2009;2(8):959-968.

12. Kwon DH, Cerqueira MD, Young R, et al. Lessons from regadenoson and low-level treadmill/regadenoson myocardial perfusion imaging: initial clinical experience in 1263 patients. $J$ Nucl Cardiol. 2010;17(5):853-857.

13. Thompson RC. Regadenoson stress in patients with asthma and COPD: a breath of fresh air. $J$ Nucl Cardiol. 2012;19(4):647-648.

14. Zoghbi GJ, Iskandrian AE. Selective adenosine agonists and myocardial perfusion imaging. J Nucl Cardiol. 2012;19(1):126-141.

15. Orlandi C. Pharmacology of coronary vasodilation: a brief review. J Nucl Cardiol. 1996;3(6 Pt 2):S27-S30.

16. Trochu JN, Zhao G, Post H, et al. Selective A2A adenosine receptor agonist as a coronary vasodilator in conscious dogs: potential for use in myocardial perfusion imaging. J Cardiovasc Pharmacol. 2003;41(1): $132-139$.

17. Zhao $\mathrm{G}$, Linke $\mathrm{A}, \mathrm{Xu} \mathrm{X}$, et al. Comparative profile of vasodilation by CVT-3146, a novel A2A receptor agonist, and adenosine in conscious dogs. J Pharmacol Exp Ther. 2003;307(1):182-189.

18. Prenner BM, Bukofzer S, Behm S, Feaheny K, McNutt BE. A randomized, double-blind, placebo-controlled study assessing the safety and tolerability of regadenoson in subjects with asthma or chronic obstructive pulmonary disease. J Nucl Cardiol. 2012;19(4):681-692.

19. Al Jaroudi W, Iskandrian AE. Regadenoson: a new myocardial stress agent. J Am Coll Cardiol. 2009;54(13):1123-1130.

20. Gao Z, Li Z, Baker SP, et al. Novel short-acting A2A adenosine receptor agonists for coronary vasodilation: inverse relationship between affinity and duration of action of A2A agonists. J Pharmacol Exp Ther. 2001;298(1):209-218.

21. Cerqueira MD, Nguyen P, Staehr P, Underwood SR, Iskandrian AE; ADVANCE-MPI Trial Investigators. Effects of age, gender, obesity, and diabetes on the efficacy and safety of the selective A2A agonist regadenoson versus adenosine in myocardial perfusion imaging integrated ADVANCE-MPI trial results. JACC Cardiovasc Imaging. 2008;1(3):307-316.

22. Astellas Pharma US; Lexiscan Product Monograph. 2012; http://www. lexiscan.com/pdf/Product_Monograph.pdf. Accessed December 29 2013.
23. Gemignani AS, Abbott BG. The emerging role of the selective A2A agonist in pharmacologic stress testing. J Nucl Cardiol. 2010;17(3): 494- 497.

24. Lieu H, Shryock J, von Mering G, et al. Regadenoson, a selective A2A adenosine receptor agonist, causes dose-dependent increases in coronary blood flow velocity in humans. J Nucl Cardiol. 2007;14(4):514-520.

25. Gordi T, Frohna P, Sun HL, Wolff A, Belardinelli L, Lieu H. A population pharmacokinetic/pharmacodynamic analysis of regadenoson, an adenosine A2A-receptor agonist, in healthy male volunteers. Clin Pharmacokinet. 2006;45(12):1201-1212.

26. Gordi T, Blackburn B, Lieu H. Regadenoson pharmacokinetics and tolerability in subjects with impaired renal function. J Clin Pharmacol. 2007;47(7):825-833.

27. Doukky R, Morales Demori R, Jain S, Kiriakos R, Mwansa V, Calvin JE. Attenuation of the side effect profile of regadenoson: a randomized double-blinded placebo-controlled study with aminophylline in patients undergoing myocardial perfusion imaging. "The ASSUAGE trial". J Nucl Cardiol. 2012;19(3):448-457.

28. Doukky R, Rangel MO, Dick R, Wassouf M, Alqaid A, Margeta B. Attenuation of the side effect profile of regadenoson: a randomized double-blind placebo-controlled study with aminophylline in patients undergoing myocardial perfusion imaging and have severe chronic kidney disease: the ASSUAGE-CKD trial. Int J Cardiovasc Imaging. 2013;29(5):1029-1037.

29. Doukky R, Rangel MO, Wassouf M, Dick R, Alqaid A, Morales Demori R. The safety and tolerability of regadenoson in patients with end-stage renal disease: the first prospective evaluation. J Nucl Cardiol. 2013;20(2):205-213.

30. Ananthasubramaniam K, Weiss R, McNutt B, Klauke B, Feaheny K, Bukofzer S. A randomized, double-blind, placebo-controlled study of the safety and tolerance of regadenoson in subjects with stage 3 or 4 chronic kidney disease. J Nucl Cardiol. 2012;19(2):319-329.

31. Leaker BR, O'Connor B, Hansel TT, et al. Safety of regadenoson, an adenosine $\mathrm{A} 2 \mathrm{~A}$ receptor agonist for myocardial perfusion imaging, in mild asthma and moderate asthma patients: a randomized, double-blind, placebo-controlled trial. J Nucl Cardiol. 2008;15(3):329-336.

32. Husain Z, Palani G, Cabrera R, et al. Hemodynamic response, arrhythmic risk, and overall safety of regadenoson as a pharmacologic stress agent for myocardial perfusion imaging in chronic obstructive pulmonary disease and bronchial asthma patients. Int $J$ Cardiovasc Imaging. 2012;28(7):1841-1849.

33. Henzlova MJ, Cerqueira MD, Mahmarian JJ, Yao SS; Quality Assurance Committee of the American Society of Nuclear Cardiology. Stress protocols and tracers. J Nucl Cardiol. 2006;13(6):e80-e90.

34. Thomas GS, Miyamoto MI. Should simultaneous exercise become the standard for adenosine myocardial perfusion imaging? Am J Cardiol. 2004;94(2A):3D-10D; discussion 10D-11D.
International Journal of COPD

\section{Publish your work in this journal}

The International Journal of COPD is an international, peer-reviewed journal of therapeutics and pharmacology focusing on concise rapid reporting of clinical studies and reviews in COPD. Special focus is given to the pathophysiological processes underlying the disease, intervention programs, patient focused education, and self management protocols.

\section{Dovepress}

This journal is indexed on PubMed Central, MedLine and CAS. The manuscript management system is completely online and includes a very quick and fair peer-review system, which is all easy to use. Visit http://www.dovepress.com/testimonials.php to read real quotes from published authors. 